Lake and was fairly plentiful flying up from the low bushes which surrounded the pond, there being no trees, but the females were crawling around probably due to the heavy body of the female, and very rare.

$\$$ type, Attean Pond, Maine, October 3, 1909, in my collectior.

${ }^{\top}$ cotypes, Attean Pond, Maine, October 3, 1909, distributed in the following collections: Boston Society of Natural History, William Reiff, G. H. Field, F. X. Williams, A. J. Crocker, University Museum of Harvard College and ten in mine, also in Brooklyn Institute Coll. from Dr. Hulst, Maine. $\odot$ cotypes, G. H. Field, William Reiff, and five in mine.

Mr. Guy Lucas turned up this interesting species in Moosehead Lake region, northern Maine, and I recognized it as being new and was going to describe it as "lucasi" when I took a trip to Brooklyn, N. Y., and saw my lucasi labelled rubiferaria Hulst from Maine. I looked up the literature and found Doctor Hulst never described this so I propose to keep it under the original name to avoid future controversy.

\title{
A NOTE REGARDING THE LIFE HISTORY OF ASCODIPTERON.
}

In a recent letter from my friend, Mr. F. Muir, he announces the sending of a paper which embodies results of his studies regarding the life history of Ascodipteron; and as it may be some months before his report can be published, it seems wise to offer this short preliminary notice. Mr. Frederick Muir, while engaged in collecting insect parasites in the Dutch East Indies, has made the following observations regarding the life cycle of Ascodipteron:

By the wings and the entire structure of the male, it proves to be very closely allied to the Streblidæ. The female is at first fully winged, but imbeds herself in the bat hosts, cuts off her wings and legs, and undergoes a. post-imaginal metamorphosis which converts her into the flask-shaped grub originally described by Doctor Adensamer. This is brought about by the abdomen growing to an enormous extent, and completely covering the head and thorax. The proboscis of the female is greatly altered to enable her to penetrate the skin of the host, but its homology to the proboscis of the normal fly is perfectly clear. A more complete and detailed description of this bizarre type will follow in a later number.

Thomas Barbour. 

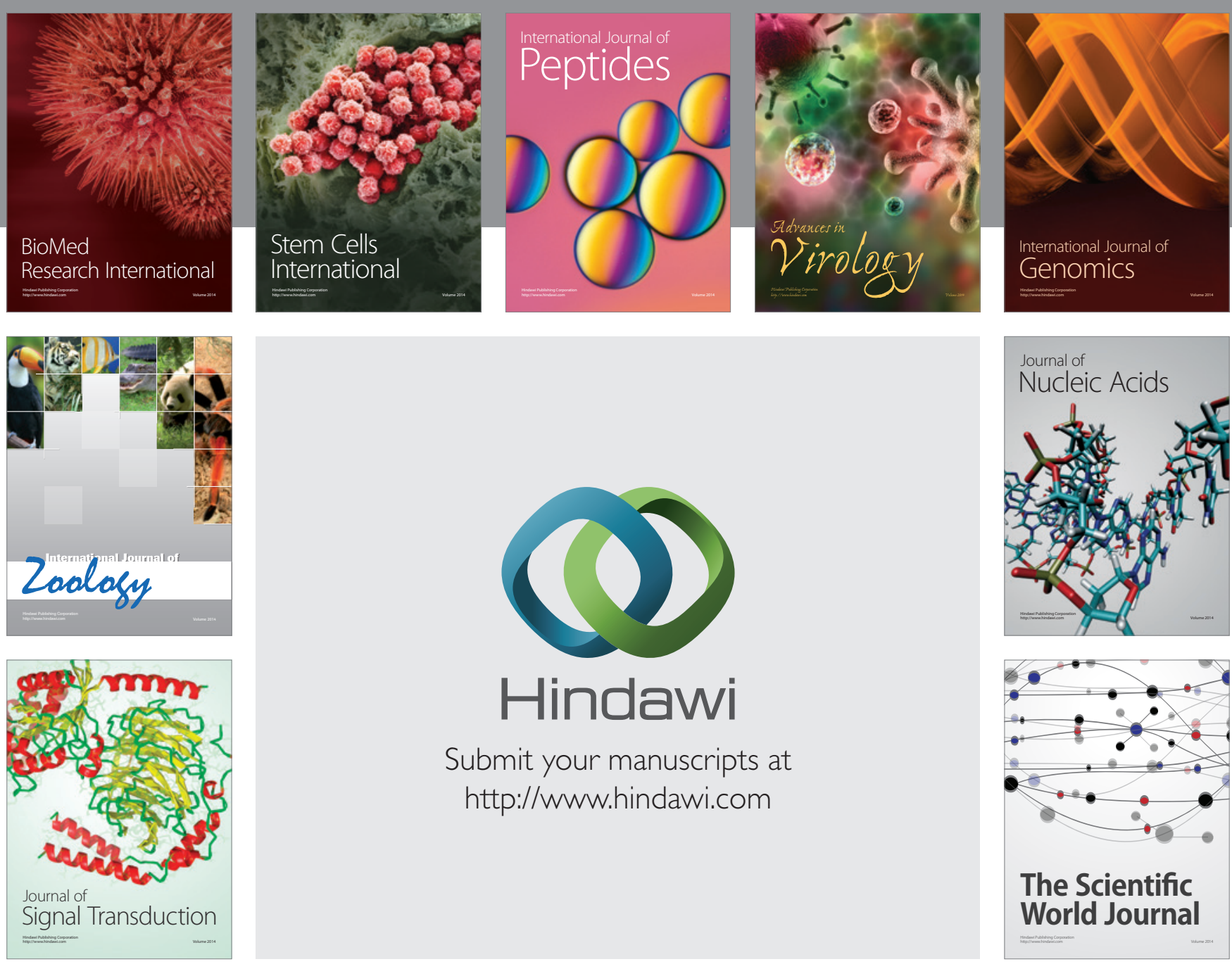

Submit your manuscripts at

http://www.hindawi.com
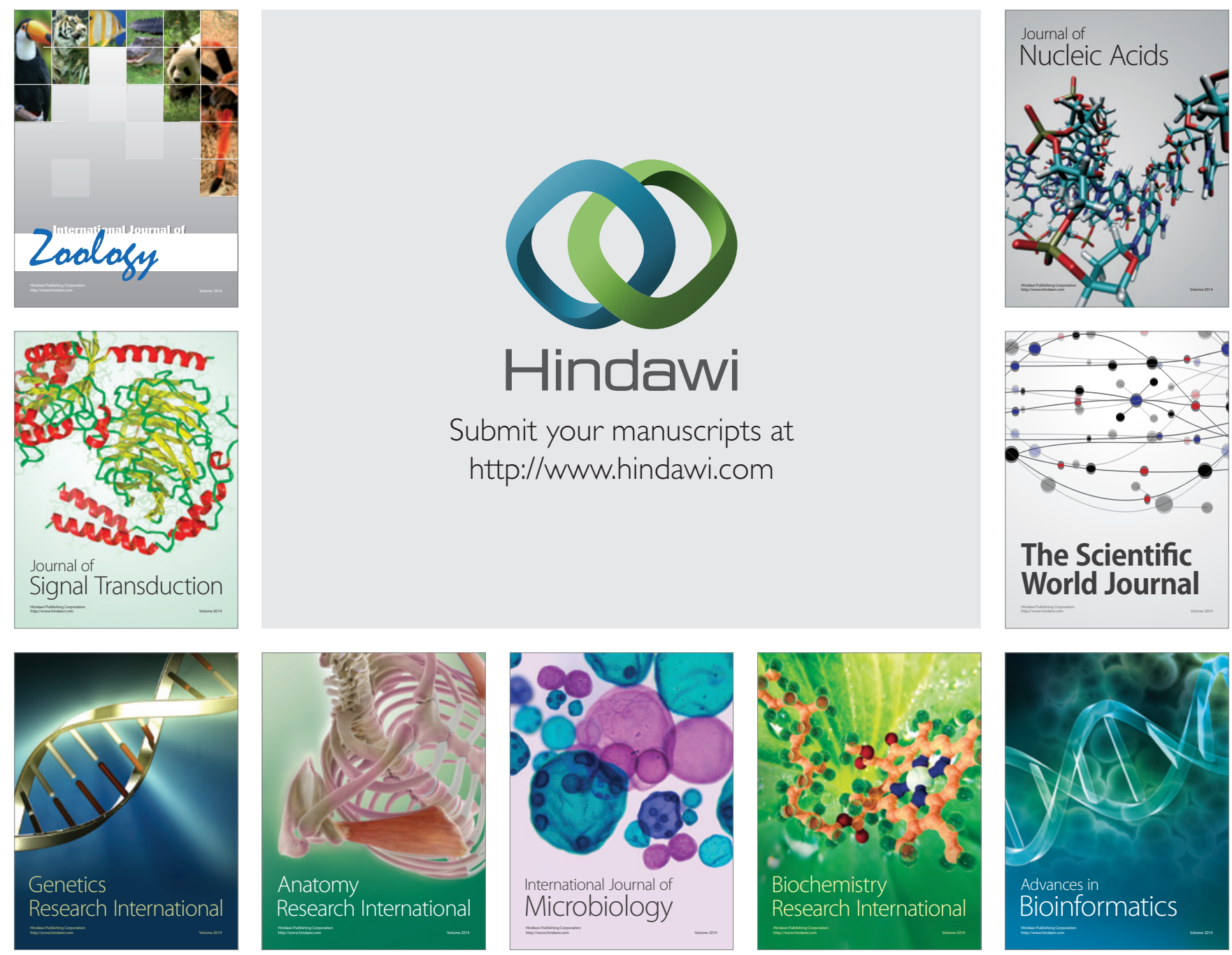

The Scientific World Journal
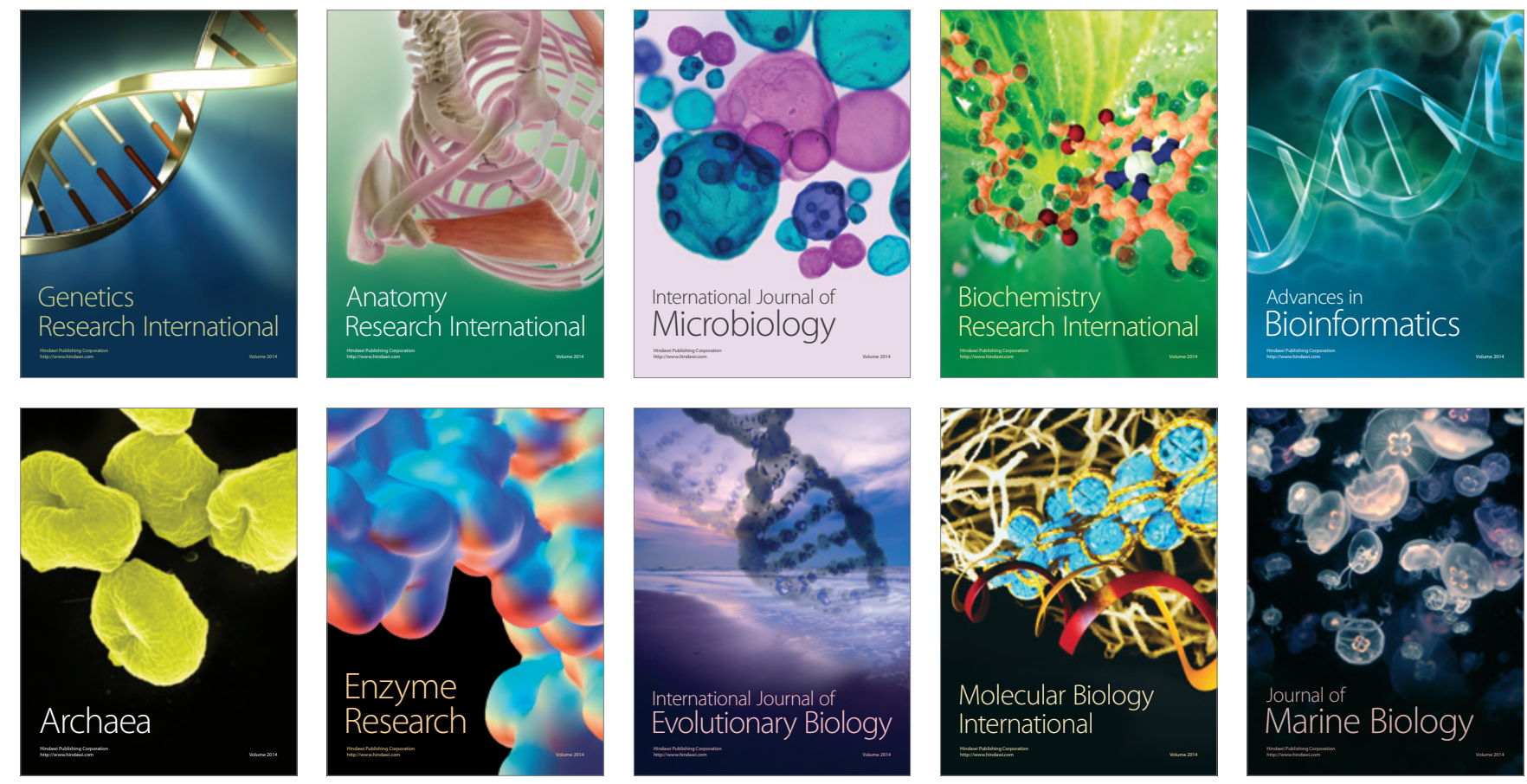